\title{
Factors Influencing Tacit Knowledge in Construction
}

L. Jawahar Nesan (Department of Civil and Construction Engineering, College of Engineering \& Applied Sciences, Western Michigan University, Michigan, USA)

\section{ABSTRACT}

Increased complexity of the construction business and consequent use of new management concepts and technologies led construction organisations to focus more on the transfer of explicit knowledge. However, it is the tacit knowledge that determines the construction companies' competitiveness in a business that is driven by turbulent market conditions and customers' everincreasing demands. This paper highlights the importance of tacit knowledge sharing in construction, explores the challenges and opportunities to efficiently share tacit knowledge, and based on the literature review identifies some critical factors that influence tacit knowledge in construction. It is argued that employees' knowledge sharing (learning) behaviours are influenced by work practices that are borne by respective organisational behaviours. Organisational cultural, and project characteristics that facilitate knowledge sharing among construction employees are explored and the practices that influence the construction employee behaviour in sharing tacit knowledge are highlighted.

Keywords: tacit knowledge, knowledge transfer, construction knowledge behaviour, knowledge management, learning organization.

\section{INTRODUCTION}

Improving construction industry performance through efficient knowledge management is a great challenge as the industry is constrained by its unique characteristics such as fragmentation, use of relatively low technology, antagonistic procurement policies, nature of contracts and the tight inspection process (Gann and Slater, 2000). Specifically, the know-how of sharing tacit knowledge in construction is hard to conceptualise, as construction organisations are inadequately addressed in the knowledge management literature. Tacit knowledge is defined by Howells (1996) as "non-codified, disembodied know-how that is acquired via the informal take-up of learned behaviour and procedures".

Nwilo and Osanwuta (2003) support the view that knowledge is scattered among various types of sources (for example, paper files and computer media), which can only be understood by specific experts or by the shared experience of an organisation. The organisation and management of the construction industry itself constrains knowledge transfer activity and restricts parties to apply knowledge (Barrett et al., 2001). The demand for reduced project duration and time availability to assess lessons learned from previous projects often act as barriers to share knowledge among construction parties. It has been argued that the construction industry is infamous for the barriers it places in the way of knowledge transfer (CERF, 2000). The desire for construction firms to apply knowledge management has come more from a fear of being left behind by competitors than from the belief in the benefits of knowledge management (Yisa, 1996). Tacit knowledge sharing is more critical especially to construction organisations to achieve competitiveness due to the following reasons:
- $\quad$ unlike manufacturing and other sectors, due to the temporary nature of and short-term relationships between project teams, the transfer of knowledge from one project to the next and from one firm to the other becomes extremely difficult;

- construction knowledge is often tacit, retained by the individuals and organisations and finally disappears once the project is closed out;

- the fragmented nature of the construction environment; and

- $\quad$ several unprecedented problems are solved during the project, which are difficult to document for others to learn.

Tacit knowledge sharing in a business environment should facilitate distributing such intelligence among relevant parties and individuals. In a 1999 survey of Fortune 1000 executives in US, $97 \%$ of respondents said that companies would benefit from more employees having knowledge, which is currently within a few people, and $87 \%$ said costly mistakes were occurring because employees lacked the right knowledge when it was needed (Macro, 2003). Organisations and individuals participating in a construction project bring their own unique skills, resources, experience and knowledge but they are not shared. Despite the interest and the effort put into knowledge management by many leading companies, the discipline is still in its infancy. In construction, many practitioners and researchers have acknowledged the limitations of current approaches to knowledge management. The key reasons for these limitations include (Rezgui et al., 2002; Gann and Slater, 2000, Barrett et al., 2001):

- much construction knowledge resides in the minds of the individuals working within a particular project;

- the motive behind decisions is often not recorded or documented; it requires a complex process to track and record thousands of ad-hoc messages, phone calls, memos, and conversations that comprise much project-related information;

- $\quad$ people responsible for collecting and archiving project data do not understand the specific needs of those who will use them;

- the project-related data is usually not used but instead it is captured and archived at the end of the construction stage; people who have knowledge about the project are likely to have left for another project and hence their experiences are not distributed; and

- lessons learned are not organised well and it is difficult to capture and transfer useful knowledge to other projects.

The above limitations all impede the sharing of tacit knowledge among individuals and organisations in construction. Tacit knowledge is hard to formalise making it difficult to communicate or share with others because it is bound to the senses, personal experiences, beliefs, values and body language which cannot be easily passed on to others. However, it is this knowledge that brings competence and skills to the individuals in construction and thus to the organisation as a whole. In fact, it requires close physical proximity while the work is being done. On the other hand, explicit knowledge is systematic and easily communicated in the 
form of hard data or codified procedures (Nonaka and Takeuchi, 1995).

Another dimension of tacit knowledge is its capability over the traditional information technology (IT) systems in providing competitive advantage to a firm. Firms cannot expect IT to produce sustainable competitive advantages because most IT capabilities (and packages) are readily available to all firms in a competitive market and no difference in performance improvement can be noticed between two competing firms when both implement suitable IT systems. Firms wishing to implement IT can easily avail themselves of the know-how and achieve the desirable results of their competitors. But tacit knowledge, which cannot be formulated in instruction manuals and data bases, which cannot be transmitted by means of electronic mail, internet or intranet, and which cannot be encapsulated numerically or alphabetically, is probably the part of the knowledge base which in the information and knowledge society will make the difference in creating and sustaining competitive advantages for companies (Johannessen et al., 2000). This is even more relevant to construction as it is still dominated by craft work.

This paper identifies the most critical factors that influence the tacit knowledge sharing in construction and discusses how those factors impact upon each other in facilitating knowledge sharing among individuals and parties in construction. Specifically, the employees' knowledge sharing behaviours and the work practices that promote those behaviours are identified. To effectively incorporate these work practices in construction firms, a set of suitable organisational characteristics and cultures are also proposed based on the findings and propositions reported in the literature.

\section{FACTORS INFLUENCING TACIT KNOWLEDGE IN CONSTRUCTION}

The key challenge of knowledge-based technology transfer is how to convert tacit knowledge to/from explicit knowledge, so that it is in a format that can be readily absorbed by construction firms (Barrett and Sexton, 1999). As tacit knowledge involves intangible factors embedded in personal beliefs, experiences and values, the method of transferring tacit to explicit knowledge should also have tacit dimensions. The parameters that influence the tacit dimension can be identified and relevant measures can also be established to continually assess and refine the practice of the tacit knowledge sharing in construction organisations. For instance, if teamwork, as one of the parameters, influences the tacit dimension, then different types of teamwork should provide a variety of opportunities to achieve a range of tacit knowledge sharing. Therefore, if such parameters are identified and a relevant set of measures established, then the organisation can assess themselves as to where they are, take steps and adopt appropriate strategies to effectively share tacit knowledge.

Tacit knowledge is mainly about the sharing of experiences through the process of socialisation such that the knowledge embodied within a technology/task is passed between individuals, from individuals to the organisation through the development of culture and shared mental models, and from the organisation back to individuals. It is also gained through interactive learning between organisations. This argument emphasises that both organisational and individual parameters influence the sharing of tacit knowledge. While 'organisational behaviours' cannot be dissociated from 'individual behaviours', the following discussions attempt to initially map the knowledge sharing parameters associated with these two behaviours.

A study of knowledge management projects found that a culture that supported knowledge sharing was highly correlated with project success (Davenport et al., 1997). Construction organisations with practices that limit the capability, autonomy, responsibility and where sharing of knowledge is discouraged either by official or unofficial policy, will not find operational efficiencies (Tushman and O'Reilly, 1997). Organisational culture refers to the deeply seated values, norms and practices shared by the employees who make up the organisation. Together with the structure, culture forms the tactical part of the organisation. Practices are the most visible symbol of culture, and they provide the most direct way for changing behaviours needed to support knowledge (De Long, 1997). New behaviours resulting from new practices will change norms over time, which will provide long term support for more effective knowledge use. These observations lead to identifying the linkage between the organisational culture, practices and individuals' behaviours as shown in Figure 1 (De Long, 1997; Tushman and O'Reilly, 1997; Beijerse, 2003; Davenport et al., 1997, Martins and Terblanche, 2000).

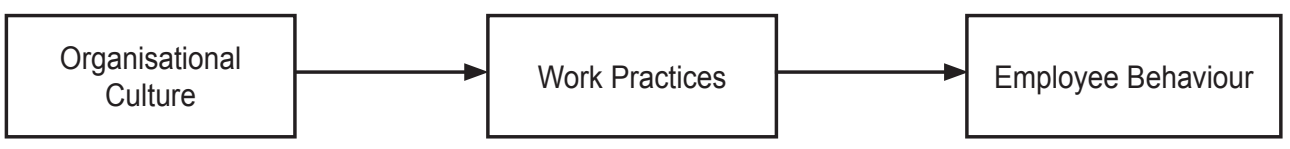

Figure 1: Factors influencing tacit knowledge

This means that appropriate organisational characteristics along with suitable work practices influence the employees' behaviour in sharing tacit knowledge. As construction organisations are project-oriented and have their unique characteristics due to transient and complex environments, their cultural behaviours are largely driven by both the organisational structure and individual project characteristics. To further develop the linkages shown in Figure 1, within the context of the construction environment, the next logical step is to answer questions such as: what are the behaviours required of construction employees to efficiently share tacit knowledge; how those behaviours can be efficiently handled and by what work practices; and how construction organisational behaviours and relevant characteristics influence those work practices? The following sections answer these questions, identify the key parameters of respective factors (organisational culture, work practices, and employee behaviours) and discuss how they facilitate and/or inhibit tacit knowledge sharing in construction.

\section{CONSTRUCTION EMPLOYEE BEHAVIOURS AND WORK PRACTICES THAT INFLUENCE TACIT KNOWLEDGE SHARING}

At the root of knowledge management is the increased recognition that knowledge sharing is a human behaviour and cannot be fostered without genuine trust and care. Through genuine leadership behaviours, organisations can be socialised to be competent in knowledge sharing (Ives et al., 2000). For instance, empowering employees for generating and sharing knowledge is the task of management. Motivating employees in knowledge 
sharing involves flexible job design, diverse and contingency style of leadership (Lam and Tang, 2003). As individuals join organisations, they bring learned behaviours from experiences that either promote or inhibit sharing of tacit knowledge. To exploit the tacit knowledge of employees in a construction environment, construction employee behaviours that are influenced by the construction organisational characteristics need to be identified and exploited properly. Some of the critical construction employee behaviours that influence tacit knowledge sharing include: trust, creativity, motivation, ability, and learning (Dasgupta, 1988; Latham, 1994; Nonaka and Takeuchi, 1995; Davenport et al., 1997; Tushman and O'Reilly, 1997; Egan, 1998; Egbu and Botterill, 2001; Robinson et al., 2001; Ives et al., 2000; Gordon, 2000; Martins and Terblanche, 2000; Yahya, 2002; Barrett et al., 2001; Tsui, 2002). The work practices that influence employees' knowledge sharing behaviours are discussed below and some critical practices are highlighted.

\section{Trust}

Employee behaviour is a complex issue influenced by many factors. It involves trust as well as the capabilities and motivation that give rise to performance behaviour. Trust reduces risk and uncertainty through better communications. Communication and the ability to work in teams are seen as the basis for trust building. Trust forms part of relationships. When individuals work in trusting teams they will have the ability to be flexible and respond to changes in information. This is seen as a very valuable approach in construction, where information may be incomplete at the time of contract and changes often arise as a project progresses. A company that is going to work in trusting teams needs to have the organisation's leadership support for this approach. Any policy that pursues trust in working relationships between employees has to come from the top. Sako (1992) defined trust as a mutual expectation that partners will not exploit the vulnerabilities created by cooperation, and that the decision over whether to trust or not depends on the interpretations of other parties' intention and possible behaviour. It is essentially a state of mind; a belief or an explanation held by one trading partner about another that the other would behave in a mutually acceptable manner. Dasgupta (1988) suggests that trust will not evolve in circumstances where an individual does not know fully the motivation of the person with whom he is considering a transaction. Once trust is established, then knowledge sharing is part of every thing in the organisation's culture (Egan, 1998). The absence of trust within project teams has been highlighted in both the Latham (1994) and Egan (1998) reports as a major factor leading to the failure of construction projects. Communication and the ability to work in teams are seen as the basis for trust building. Due to the project nature of construction, where people form temporary project-based teams, this is not always possible. However, when individuals work in trusting teams they have the ability to be flexible and respond to changes of information. Conflict can build trust if project teams can move away from a 'blame culture' to a 'problem solving culture'. Some of the methods (work practices), as identified from the above discussion, that improve trust between individuals include: face to face interaction; external meeting places; long term relationships; experience (working together); problem solving; shared goals; and reciprocity. These attributes while improving trust also promote tacit knowledge sharing between individuals.

Face-to-Face Interaction: Face-to-face interaction is a traditional approach of sharing tacit knowledge (socialisation). Face-to-face interactions also help in increasing the organisation's memory, developing trust and encouraging effective learning. It provides strong social ties and shared understandings that give rise to collective sense making.
Long-term relationships: In construction, partnering possesses many of the characteristics of a long-term relationship. It enables all parties to experience the job together and provides opportunities to carry over the knowledge from one project to the other. Other long term relationships include strategic alliances, joint ventures and consortiums.

Experience: Individuals learn the tacit part of the knowledge and skill by working together. Continually communicating through action and outcome develops trust.

Problem Solving: Construction problems are often unprecedented and they must be solved immediately before becoming disputes. Problem solving to mutual satisfaction improves trust between individuals and allows them to learn the tacit knowledge related to the problem.

Shared Goals: Shared goals improve communication between individuals and creates mutual understanding between them as they concentrate on the same goal. This means that the members of the project team understand each other's position, appreciate the requirements and difficulties they experience and strive to meet each other's expectations.

Reciprocity: Individuals should often look for opportunities to return for favours and assistance they receive from their counterparts. Failure to do so can stop a relationship before it starts.

Honest Communications: Individuals have to be open and honest in sharing the information that reflects the real situation of the business. It helps fostering a personal relationship promoting feedback between them.

\section{Creativity}

Creativity is one of the prerequisites for efficient practice of tacit knowledge as it focuses on the nature of the thought process and intellectual activity, which generate new insights or solutions to problems. The concept of creativity can be defined as the generation of new and useful/valuable ideas for products, services, processes and procedures by individuals or groups (Ford, 1995). Creativity can vary from one group or one culture to another and it can also change over time. Evaluating creativity should therefore be considered at the level of a person, organisation, industry, and profession. Covey (1993) claims that creativity lies in a shared vision and mission that focus on the future. In a creative organisation, such vision and mission are customer- and market-oriented, focusing on solving customer's problems (CIMA Study Text, 1996). Tushman and O'Reilly (1997) claim that quick decision-making leads to fast work rates and promotes creativity. Quick decision making, in turn, can be efficiently achieved through empowering employees and business units as empowerment seeks to decentralise decision-making authority. The degree to which employees have freedom and authority to participate in decision making in solving problems determines the level of empowerment, which is positively related to the level of creativity in the organisation (Martins and Terblanche, 2000). Empowerment also drives individuals to constantly seek knowledge to improve their performance by involving them in various efficacy activities including leadership, process improvement, participation, and teamwork (Jawahar Nesan, 2004). Employees are closest to the problem and are most likely to have the best creative solutions; therefore their involvement is critical. Informal sharing of views and ideas through events such as brainstorming on the other hand can increase creativity. Brainstorming helps in problem solving and in creating new knowledge from existing knowledge (Tsui, 
2002). Based on the above discussion, some of the practices that help achieve creativity among individuals include brainstorming, employee participation in decision making and empowerment.

Brainstorming: Brainstorming is a process where a group of people meet to focus on a problem or idea, and explore such ideas with a view to coming up with solutions, or further developing the ideas. The participants express or contribute their ideas as they strike them and then build on the ideas raised by others.

Empowerment: Empowerment is a process of enhancing feelings of self-efficacy among organisational members through the identification of conditions that foster powerlessness and through their removal by both formal organisational practices and informal techniques of providing efficacy information (Conger and Kanungo, 1988). Empowerment enables individuals to acquire tacit knowledge and obtain mastery in their business.

Employee Involvement: As employees are unlimited sources of knowledge, distribution of knowledge without their involvement is difficult. As employees are closest to the problem and most likely to have the best solutions, their direct involvement improves creativity.

Time: In organisations where creativity and knowledge sharing are encouraged, employees should have time to think creatively and experiment on it. Some percent of their time should be allowed to work on generating new ideas and their favorite projects.

Customers' Feedback: Creativity can also be increased through feedback from owners, which can help understand the needs of owners and promote knowledge sharing.

Quick Decision Making: The speed of decision-making can also promote or inhibit sharing of tacit knowledge. A cultural norm that leads to quick decision-making facilitates fast working rates and promotes creativity.

\section{Motivation}

Motivation is a vital behaviour in bringing about the effective utilisation and sharing of knowledge. Motivating individuals to create, share and use knowledge is a critical success factor for all knowledge management projects (Davenport et al., 1997). Motivating people to become more knowledge competent does require an understanding of care (Gordon, 2000). Individuals with a supportive work environment are also likely to have high motivation (Ives et al., 2000). Issues that influence motivation of construction employees include material availability, tool availability, rework, crew interfacing, overcrowded areas, inspection delays, craft-worker absenteeism, foreman changes and incompetence of foremen (Lam and Tang, 2003). According to Robinson et al. (2001), there is a need to develop incentive and reward structures to motivate employees and exploit tacit knowledge in construction. Rewarding the employees for completing a critical job task, saving work time, and participating in a dialogue on useful and interesting issues motivate employees (Finerty, 1997). Davenport et al. (1997) argued that in order to get creative people to share their knowledge, suitable changes in incentive and reward systems are necessary. Proper job design, availability of resources, and open communication also motivate individuals to practice tacit knowledge.

Successful motivation depends on situational factors. To achieve success, the situation should be analysed and an appropriate strategy be adopted to motivate individuals in that particular situation. This contingency approach includes adoption of appropriate leadership styles, recognition schemes, incentives, learning programs, decision making authority, open communication, and an appropriate physical work environment (Jawahar Nesan and Holt, 1999). In Maslow's motivational model, the higher order needs of employees are influenced my job enrichment factors such as responsibility, growth, recognition, achievement, work autonomy, challenging job, and decision making authority (Lam and Tang, 2003, Jawahar Nesan and Holt, 1999). Job dissatisfaction and demotivation arise where there is lack of independence and control for employees over their own processes (Reynolds and Shister, 1949; Likert, 1961). Therefore, job design must satisfy job enrichment if the higher order needs are to be satisfied. It must be noted here that most of these enrichment factors that satisfy the higher order needs also empower individuals. Empowerment deals with the psychological behaviour of individuals and makes them committed toward attainment of self-efficacy. Based on the above discussion, some of the practices that help motivate individuals include care, job design, open communication, effective rewarding system, contingency style of leadership, and empowerment.

Care: To care for someone is to help them to learn, to increase an awareness of events and consequences and help create personal knowledge, while sharing insights.

Job Design: A productive and meaningful job creates satisfaction at all levels of construction employees. A construction job will become productive by adequately planning and insuring that materials, manpower and supporting data are readily available. Some basic principles of designing meaningful jobs are job enrichment by increasing decision-making opportunities for individuals, job rotation to reduce boredom and increase skills, and a team approach.

Open Communication: Communication channels for different organisational levels should be established for the exchange of information and workers' involvement in decision-making. Technical problems, dissatisfactions or misunderstanding can be solved directly through site meetings, telephone calls and e-mails.

Effective Rewarding System: Under the rewarding system, employees should be treated fairly and equally by clearly defining and communicating the system to them, making honest appraisals, and rewarding according to the effort of participation, performance, skill level and desired behaviour of the employees.

Contingency Style of Leadership: Working for a credible leader who inspires confidence among employees increases motivation and commitment. Diverse and contingency style of leadership is required of the construction managers as they are expected to lead the subordinates working at different environments with different requirements.

Empowerment: Empowerment enhances employees' feelings of personal mastery and self-determination, encourages participation by all parties in decision-making, and results in democratic distribution of power. It increases satisfaction, self-efficacy, loyalty and thus motivation of employees.

\section{ABILITY (SKILLS)}

A common problem in construction firms is the difficulty in attracting staff/employee with the appropriate aptitude and ability to undertake work and drive knowledge sharing (Barrett et al., 2001). The study group of IBM (Smack and Dawson, 1993), after evaluating programs used in IBM and other companies, concluded that an activity-based learning approach should be adopted to improve the skill base of the employees. In construction, this 
has been supported by Maloney (1994) as saying that workers trained with an activity-based approach are more likely to possess a broader set of skills. The need to develop the ability of staff through training, job rotation and apprenticeship is suggested in the construction literature. Learning through apprenticeship improves skill levels of employees and it is a strong source of tacit knowledge to learn a particular craft (Eraut, 2000). In a partnership process where employees are attached or assigned, their colleagues/superiors can share more tacit knowledge and improve skills through mentoring and vicarious experience. Such approaches in construction are strongly suggested by a survey conducted by Kululanga et al. (1999) and a self-development learning model developed by Jawahar Nesan and Holt (1999). Based on the above discussion, some of the practices that improve employees' ability (skills) include training, mentoring, and apprenticeship.

Training: Training provides an excellent environment for communication between employees on potential areas of improvement and skill development. Its effectiveness depends much on the organisation's plans and strategies that ensure knowledge transfer among employees.

Mentoring: A colleague or a senior member can act as a mentor of an employee and facilitate the development of that employee by identifying training needs and assisting on other development aspirations.

Apprenticeship: Apprenticeship is a form of training based on practical experience or learning by doing (vicarious experience). It is also connected with informal activity-based learning and organisational learning. Apprentices often work with those who have achieved mastery in the respective business and learn craftsmanship through observation, imitation and practice.

\section{LEARNING}

Enactive attainment or individuals' authentic mastery experience related to the job can be achieved through continual learning (Senge, 1990; Conger and Kanungo, 1988). Mastery experience is often derived from the source of tacit knowledge. Teamwork is one of the key practices that facilitates the construction employees' learning behaviour in sharing tacit knowledge (Kululanga et al., 1999, Jawahar Nesan, 2004). Work teams influence the degree to which learning takes place in construction organisations. Wellestablished work teams facilitate diversity and individual talents that complement one another and provide a shared space where relationships take place and promote learning which influence the sharing of tacit knowledge (Martins and Terblanche, 2000). Another important aspect of work teams is that team members trust and respect one another, understand one another's perspectives and style of functioning, solve differences of opinion, communicate effectively, question, and are open to new ideas. Effective teamwork is partly based on team member's skills and abilities and partly on the shared values within the group.

\section{THE CHARACTERISTICS OF THE CONSTRUCTION ENVIRONMENT THAT FACILITATE THE WORK PRACTICES THAT INFLUENCE KNOWLEDGE SHARING BEHAVIOURS}

This section identifies the organisational, cultural and project characteristics that inhibit and promote respectively the work practices that facilitate the employee knowledge sharing behaviour in construction.

\section{Construction organisational and cultural characteristics}

The traditionally fragmented nature of the construction industry leads to confrontation and litigation and becomes a barrier to knowledge production in organisations where employees are reluctant to change routines (Egan, 1998). According to De Long (1997), the cultural characteristics that lead an organisation to achieve the ability to leverage knowledge through interaction include discussing sensitive topics, senior management's approachability, volume of interactions, level of collective responsibility, orientation to existing knowledge and expertise, knowledge sharing, teaching, and attitude towards mistakes. These characteristics broadly address some organisational issues such as communication and leadership strategy. An organisational culture that supports open and transparent communication, based on trust, will have a positive influence on promoting knowledge productivity. The leadership must establish suitable strategy, vision and mission that enhance knowledge sharing among employees (Covey, 1993). The strategy that promotes the development and implementation of new and existing knowledge is critical for successful implementation of knowledge management (Beijerse, 2003). The strategic goals and objectives reflect the priorities and values of organisations and as a result may promote or hinder creativity and knowledge sharing.

The basic elements of organisational culture (such as shared values, beliefs and behaviours) influence knowledge productivity in many ways, but significantly in two ways (Martins and Terblanche, 2000; Barrett and Sexton, 1999; Johannessen et al., 2000). First, through socialisation processes in organisations, individuals learn what behaviour is acceptable and how activities should function. Second, the basic values, assumptions and beliefs become enacted in established forms of behaviours and activity and are reflected as structures, policy, practices, and procedures. This indicates that organisational structure, socialisation, policy and procedures largely influence the knowledge sharing behaviour among employees. The organisational structure should be flexible enough for the employees to socialise among themselves and have inherited the characteristics of autonomy, empowerment, participation in decision-making, and group interactions if knowledge sharing is to be successful (Kurul et al., 2003; Ives et al., 2000). According to Kurul et al. (2003), a flat structure, autonomy and work teams promote knowledge productivity, whereas, specialisation, formalisation, standardisation, and centralisation will inhibit knowledge productivity. Examples of flexibility in organisations are job rotations and to discard formal and rigid job descriptions.

The organisational system that reinforces all necessary supports and infrastructure including rewards and recognition, and people and technological resources promote knowledge productivity (Tushman and O'Reilly, 1997; Nelson and Winter, 1982). Intrinsic rewards like increased autonomy and improved opportunities for personal and professional growth may support the knowledge productivity. There is a growing recognition that speed is important in the development of successful knowledge sharing practice. To enable firms to share knowledge within a turbulent and complex environment, fast access to information is required. Information technology should facilitate knowledge productivity by enhancing fast delivery of information.

Innovation motivates employees to constantly acquire and share knowledge. Ideas are the starting point for innovation, and the best known and widely used technique to develop new ideas is brainstorming. It helps to free employees from 'fixed ideas'. Continuous learning culture and innovation are complementary to each other in facilitating knowledge sharing. Taking risks and experimenting with new ideas are behaviours associated with 
innovation and thus improve knowledge productivity. Knowledge productivity can be achieved in a tolerant atmosphere in which mistakes are accepted as part of experimenting and regarded as learning experience. In a way, innovation and idea generation can be considered as change management and support for change is a value that influences creativity positively (Tushman and O'Reilly, 1997). The process of handling conflict can also influence knowledge productivity as constructive conflict handling approach supports creative behaviours in organisations (Martins and Terblanche, 2000).

Collectively, based on the above discussion (Beijerse, 2003, CIMA Study Text, 1996; Gordon, 2000; Davenport et al., 1997; Robinson, 2001; Martins and Terblanche, 2000; Kurul et al., 2003; Tushman and O'Reilly, 1997; Nelson and Winter, 1982), several parameters related to organisational culture that influence knowledge productivity are depicted in Figure 2.

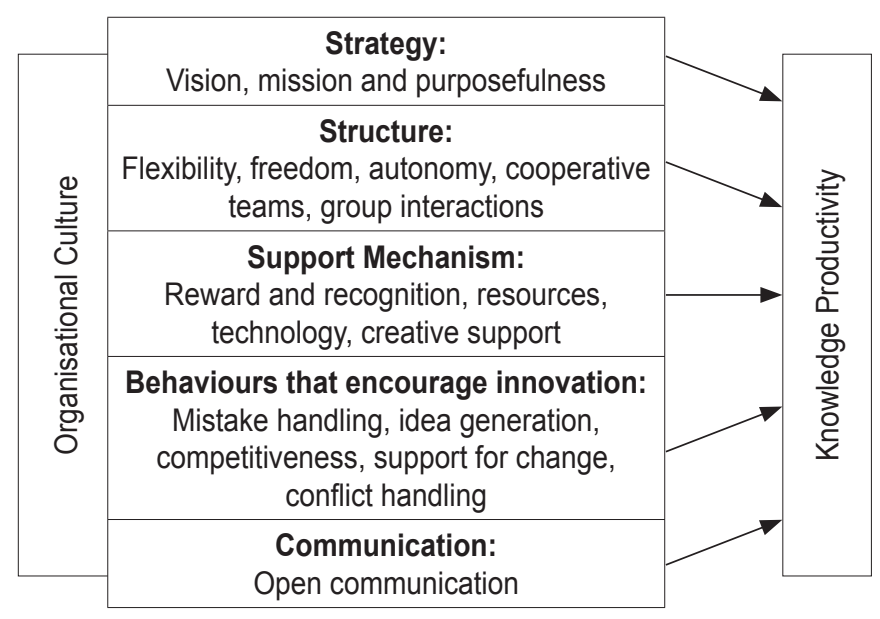

Figure 2: Parameters of organisational culture that influence knowledge productivity

Research on innovation in construction firms shows that innovation helps in introducing new products and services, creative ways of capturing, sharing and using individual experience and expertise within the company, managing people through new major organisational change, and encouraging and managing new partnering arrangements (Barrett and Sexton, 1999). Post project reviews effectively transfer knowledge to subsequent projects. Construction organisation culture that supports experimentation (trial and error) will influence tacit knowledge. Autonomous individuals are likely to share more information than non-autonomous individuals. The speed of decision-making can also promote sharing of tacit knowledge. Tushman and O'Reilly (1997) claim that a cultural norm, which leads to quick decision-making also leads to fast work rate and promotes creativity. With the importance of teams, more attention is being directed at communication between team members, which may also be referred to as lateral communication. Lateral communication involves communication with persons who do not stand in hierarchical relation to one another (Baker, 2002). Such communication between people working in teams with equal authority and responsibility improves tacit knowledge. Construction characteristics, on the other hand, that inhibit tacit knowledge include rigid management that rules out experiment and trial and error, confrontational, litigious, and fragmented industry structure, low profit margins, lack of trust, adversarial and inflexible contractual arrangements, low level of education and training, reluctance to admit mistakes, and lack of research and development (Egbu and Botterill, 2001; Kurul et al., 2003).

Based on the aforesaid discussion the organisational and cultural characteristics that promote and inhibit respectively the knowledge sharing practices are highlighted below.

\section{Promoters - Construction organisational and cultural characteristics}

A knowledge enriching culture requires innovation, management commitment and leadership, experimentation, work autonomy, quick decision-making, and lateral communications. Individuals and teams find time to think and act. Mistakes are viewed as learning opportunities.

Innovation: Construction organisations should adopt the culture of generating and implementing new ideas to effectively respond the dynamic nature of the construction business.

Management Commitment: Many of the best ideas in organisations are never put into practice. One of the main reasons is that new insights and initiatives often conflict with established mental models of top management. Top management should support new insights and initiatives in a knowledge sharing culture.

Experimentation: A construction organisation culture that supports experimentation (trial and error) will influence tacit knowledge.

Autonomy: Work autonomy motivates individuals to create new knowledge. Moreover, autonomous individuals are likely to share more information than non-autonomous individuals.

Quick Decision-making: The speed of decision-making can also promote or inhibit sharing of tacit knowledge. Cultural norms 
that lead to quick decision-making improve work rate and promote creativity.

Lateral Communication: Construction organisations evolve in many directions. Changes confronting construction organisations have made organisational communication more important to overall organisational performance. Lateral communication involves communication with persons who do not stand in hierarchical relation to one another - for example, people working in teams with equal authority and responsibility.

\section{Inhibitors - Construction organisational and cultural characteristics}

Time-oriented activity management prevents people to learn and share knowledge in project environments. As construction is a less scientific business and more craft-oriented, people are always reluctant to new ideas and changes. People involved in the business are also prudent to share their knowledge and experience, as contract terms are so rigid. It is further aggravated due to the transient nature of job placements and lack of recognition for improved performance. The characteristics of the construction organisation that inhibit the sharing of tacit knowledge include rigid management that rules out experiment and trial and error in daily practice, confrontational, litigious, fragmented industry structure, low profit margins, lack of trust, adversarial and inflexible contractual arrangements, low level of education and training, reluctance to admit mistakes, lack of research and development, time pressure, reluctance to change, reluctance to share knowledge, lack of reward, and low level of job security.

\section{Project specific characteristics}

In construction, project specific characteristics that promote sharing of tacit knowledge include a move towards change management, collaborative forms of procurement, enlightened owners, effective team composition, trust between team members, project complexity, and early involvement of contractors (Egbu and Botterill, 2001; Kurul et al., 2003). Collaborative forms of procurement tackle the fragmented nature of construction environment. The fragmentation of the industry, and its confrontational and litigious nature inhibit the sharing of tacit knowledge. Construction literature on collaborative forms of procurement often suggests a partnering approach, as it possesses the characteristics of long-term relationships and experiential learning (Haksever et al., 2001). Partnering is described as "a management approach used by two or more organisations or individuals to achieve specific business objectives by maximising the effectiveness of each participant's resources" (Bennett and Jayes, 1995). Early involvement of the contractor provides tacit knowledge related to labour, materials, and cost during the design. Team composition plays a significant role in knowledge production in project environments. The fundamental attribute of an effective team is its flexibility and responsiveness in addressing the emergent problems and opportunities. This is largely facilitated by the high-level of expertise and 'adequate knowledge-base' within the team. Team members are more willing to share knowledge if they trust one another (Jawahar Nesan, 2004). Team stability (i.e. continuous involvement of the same team members throughout the project life-cycle) is important in establishing trust between team members. The project complexity (e.g. increased number of subcontractors/suppliers, design complexity, increased variations) creates challenges, which often influence the sharing of tacit knowledge and promote knowledge production.

Based on the aforesaid discussion the project specific characteristics that promote and inhibit respectively the knowledge sharing practices are highlighted below.

\section{Promoters - Project specific characteristics}

Collaborative Forms of Procurement: Partnering is one way of ensuring collaborative forms of procurement in construction. There are three types of partnering (Haksever et al., 2001) - partnering between individuals, project partnership, and strategic partnership. Individuals working together in a coordinated fashion and helping each other in problem solving best share knowledge. A level of trust is also established while working together in one team for a long time. Unlike individual partnering, project partnering helps to share tacit knowledge between organisations. 'One-off nature' is a unique characteristic of the construction business where different parties work together for a period and disperse after the completion of the project, which impede them to share tacit knowledge in the aftermath of the completion of the project. This problem could be overcome by adopting a long-term partnership approach.

Post-project Reviews: Debriefing sessions can be held to highlight lessons learned during the course of a project. These reviews are important to capture knowledge about causes of failures, how they were addressed, and best practices. This knowledge can be transferred to subsequent projects. It is also crucial that post project review meetings take place immediately after a project is completed as project participants often move to other projects or organisations.

Repeated Owners: Repeatedly working with the same owners (through partnership arrangements) helps promote trust and eliminate the problems associated with one-off owners. It also helps in building long-term relationships, which is considered as an important factor for successful knowledge sharing.

Trust: Trust between the construction project participants eliminates the attitude of prudence and protectionism and improves knowledge sharing between them.

Early Involvement of the Contractor in a Project: With early involvement, the contractor is able to schedule the detailing to a preferred order and influence the design for optimum efficiency. This will enhance tacit knowledge sharing between the designer and the contractor.

Project Team's Continuity: The project team's continuity improves relationships between team members. It significantly influences the transfer of knowledge from one project to the next and from one firm to another. It helps in learning and sharing the lessons learned from previous projects.

\section{Inhibitors - Project specific characteristics}

Lack of appropriate team approach and trust between individuals inhibits sharing of tacit knowledge. Lack of other resources such as time and funds also prevent people from sharing tacit knowledge. The project factors that inhibit tacit knowledge sharing between parties include lack of teamwork, lack of trust between participants, unwillingness to share knowledge, transient nature, and lack of long-term relationships.

Based on the discussion in the foregoing sections, Figure 3 illustrates collectively different parameters that influence tacit knowledge in construction. It is argued earlier in this paper that appropriate 'practices' streamline employees' 'knowledge behaviour'. Such 'practices' in turn are influenced by the organisational 'characteristics'. This linkage has been substantiated in the above discussions by identifying and analysing all relevant factors associated with knowledge sharing behaviours, work practices, and organisational characteristics and their influence on tacit knowledge sharing in construction. Figure 3 is simply an elaboration of the earlier conception made in this paper 
that "the organisational culture bearing certain characteristics influences the work practices, and the work practices in turn influence employees' learning behaviours. It can be used by the construction organisations as a guideline in devising the right strategies and suitable systems to efficiently implement tacit knowledge sharing.

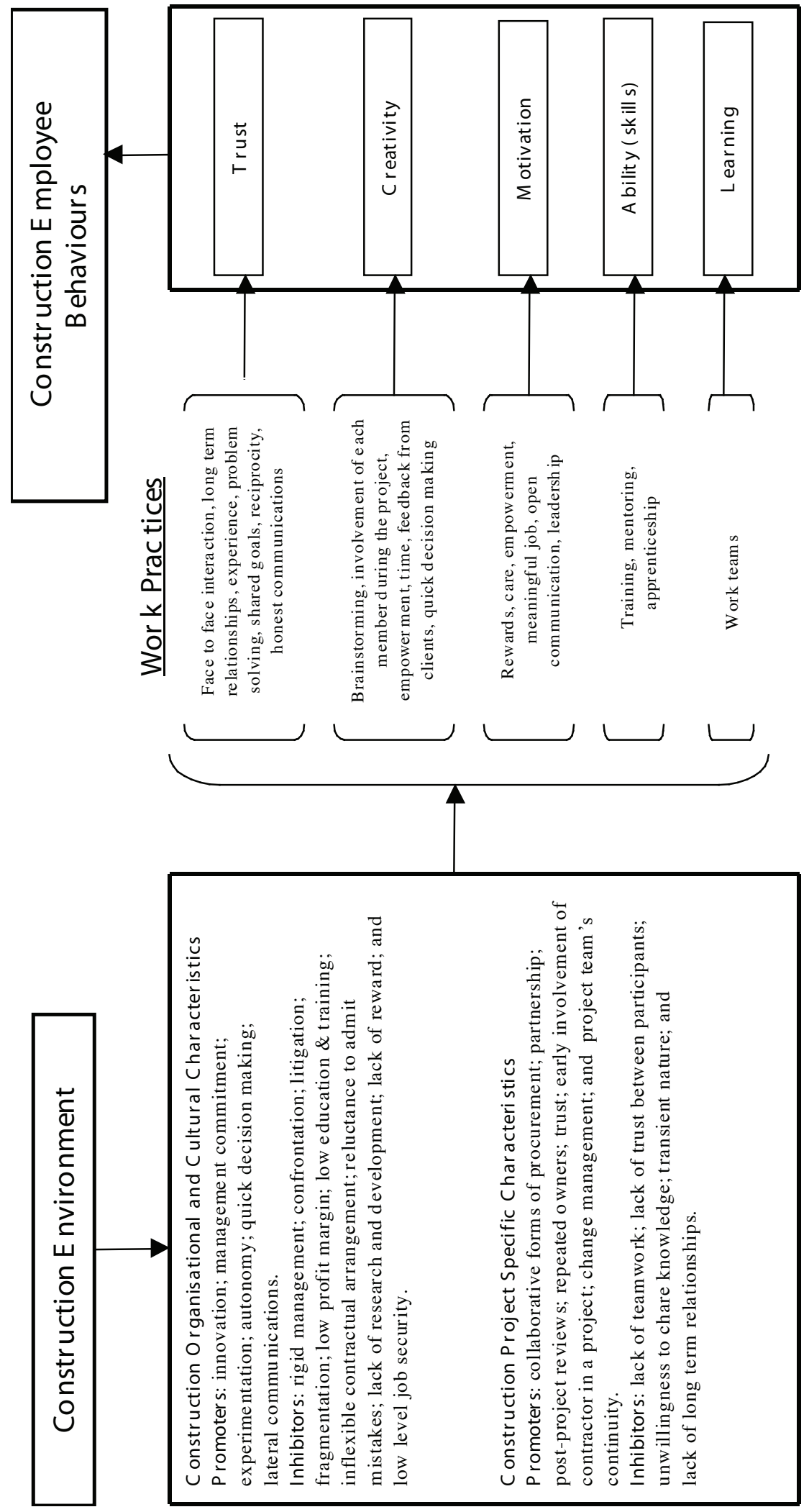

Figure 3: Parameters that influence tacit knowledge in construction 


\section{CONCLUSION}

Both inter and intra organisational knowledge distribution in construction is extremely difficult due to the temporary nature of construction business and short-term relationships between project teams. The greatest challenge is that construction knowledge, often being tacit, retained by the individuals and organisations, finally disappears once the project is completed. Although construction knowledge is explicitly available in many forms, the tacit part of that knowledge strongly influences the performance outcome, as construction is often a practice and craft-based business. The tacit knowledge is largely deposited in the minds of people making it difficult to communicate or share with others because it is bound to the senses, personal experience, beliefs, values and body language which cannot be easily passed on to others. However, it is this knowledge that brings competence and skills to the individuals in construction and thus to the organisation as a whole. As transferring this knowledge requires close physical proximity while the work is being done, both construction organisational behaviours and employee behaviours should be streamlined with appropriate characteristics and practices.

This paper identifies five major critical factors that influence employees' knowledge sharing behaviour in construction - namely trust, creativity, motivation, ability, and learning. The work practices attributing to the respective factors, as highlighted in this paper, influence employees' behaviours in efficiently sharing tacit knowledge. Construction organisational, cultural and individual project characteristics are also suggested to efficiently incorporate the work practices into day-to-day business. The organisational behaviours and work practices as suggested in this paper can be considered by construction organisations in designing their knowledge sharing system. The propositions and arguments made have also provided a new research direction seeking an in-depth future investigations on several issues related to construction work practices and organisational characteristics and their impact on the knowledge sharing behaviour of employees.

\section{REFERENCES}

Baker, A. (2002), 'Organisational communication', Journal of Business Communication, (http://www.sc.doe.gov/sc5/benchmark/ Ch\%2013\%20Organizational\%20Communication\%2006.08.02. pdf), [accessed on April 5, 2004].

Barrett, P. and Sexton, M. (1999), 'The transformation of outof-industry knowledge into construction industry wisdom', Construction Research and Innovation Strategy Panel, 98/4, UK.

Barrett, P., Sexton, M., Miozzo, M., Leho, E. (2001), Innovation in Small Construction Firms: Base Report for the EPSRC/DETR: IMI Construction-Link, University of Salford and UMIST, UK.

Bennett, J. and Jayes, S. (1995), Trusting the Team. Centre for Strategic Studies in Construction, The University of Reading, UK in Haksever, A. M., Demir, H. I., and Giran, O. (2001), 'Assessing the benefits of long-term relationships between contractors and subcontractors in the UK', International Journal of Construction Marketing, vol.3, no.1.

Beijerse, R.P. (2003), 'Knowledge Management in small and medium sized companies: knowledge management for entrepreneurs', Journal of Knowledge Management, vol.4, no.2, pp.162-179.

CERF (2000), 'Guidelines for moving innovations into practice'. Working draft guidelines for the CERF International Symposium and Innovative Technology trade show 2000, Civil Engineering Research Foundation, Washington, DC.

CIMA Study Text (1996), Organizational Management and Development, 3rd ed., BPP Publishing, London.

Conger, J.A. and Kanungo, R.N. (1988), 'The empowerment process: integrating theory and practice', Academy of Management Review, vol.13, no.3, pp.471-482.

Covey, S.R. (1993), How to Succeed with People, Deseret Book Co., Salt Lake City, Ut.

Dasgupta, P. (1988), Trust as a Commodity: Making and Breaking Cooperate Relations, Oxford: Blackwell.

Davenport, T.H., D.W. De Long, and M.C. Beers (1997), Building Successful Knowledge Management Projects, Working Paper, Ernst \& Young's Center for Business Innovation, Boston, MA.

De Long (1997), Building the knowledge based organization: How cultures drives knowledge behaviors, Working paper, Center for Business Innovation, Boston, MA.

Egan, J. (1998), Rethinking Construction: Report of the Construction Task Force on the Scope for Improving the Quality and Efficiency of UK Construction, Department of the Environment, Transport and the Regions (DETR), London.

Egbu, C. and Botterill, K. (2001), 'Knowledge management and intellectual capital: Benefits for project based industries', COBRA 2001, RICS Foundation, UK.

Eraut, M. (2000), 'Non-formal learning and tacit knowledge in professional work', British Journal of Educational Psychology, vol.70, no.1, pp.113-136.

Finerty, T. (1997), 'Integrating learning and knowledge infrastructure', Knowledge Management Journal, vol.1, no.2, pp.98-104.

Ford, C.M. (1995), 'Striking inspirational sparks and fanning creative flames: A multi-domain model of creative action taking' in Creative Action in organizations: Ivory Tower Visions and Real World Voices, C.M. Ford and D.A. Giola (eds.), Sage Publications, Thousand Oaks, pp.330-354.

Gann, D.M., and Slater, A.J. (2000), 'Innovation in Project based, service enhanced firms: The construction of complex products and systems', Research Policy, vol.29, pp.955-972.

Gordon, P. (2000), Strategy: Compelling word, Complex Concept, Knowledge Management: Classic \& Contemporary Works, The MIT Press, Cambridge, Massachusetts.

Haksever, A. M., Demir, H. I., and Giran, O. (2001), 'Assessing the benefits of long-term relationships between contractors and subcontractors in the UK', International Journal of Construction Marketing, vol.3, no.1.

Howells, J. (1996), 'Tacit knowledge, innovation and technology transfer', Technology Analysis and Strategic Management, vol.8, no.2, pp.91-105.

Ives, W., Torrey, B., and Gordon, C. (2000), Knowledge Sharing is a Human Behavior, Knowledge Management: Classic and Contemporary Works, The MIT Press, Cambridge, Massachusetts. 
Jawahar Nesan, L. and Holt, G.D. (1999), Empowerment in Construction: The Way Forward for Performance Improvement, RSP Ltd, England.

Jawahar Nesan, L. (2004), 'Efficacy-information for implementing learning in construction', The Learning Organization Journal, vol.11, no.1, pp.45-66.

Johannessen, J.A., Olsen, B., and Olaisen, J. (2000), 'Mismanagement of tacit knowledge: Knowledge management, the danger of information technology, and what to do about it', Long Range Planning, vol.30, no.1, pp.96-109.

Kululanga, McCaffer, Price and Edum-Fotwe (1999), 'Learning mechanisms employed by construction contractors, Journal of Construction Engineering and Management, July-August, pp. 215223

Kurul, E., Egbu, C., Quintas, P., Hutchinson, V.J., Anumba, C. and Ruikar, K. (2003), Knowledge Production, Sources and Capabilities in the construction industry, Report to the DTI, Knowledge Management for Sustainable Construction Competitiveness Consortium, UK.

Lam, S. and Tang, C. (2003), 'Motivation of Survey employees in construction projects', Journal of Geospatial Engineering, vol.5, no.1, pp.61-66.

Latham, M. (1994), Constructing the Team, Final Report of the Joint Government/Industry Review of Procurement and Contractual Arrangements in the UK Construction Industry, UK.

Likert, R. (1961), New Patterns of Management, McGraw-Hill, New York.

Macro, D., (2003), 'Enterprise Warehousing solutions: A Meta-data repository is the key to knowledge management', (http://www.tdan. com/i024fe02.htm), [accessed on Sep.28, 2003].

Maloney, W.F. (1994), 'Strategic planning for human resource management', in proceedings of the A.J. Etkin International Seminar on Strategic Planning in Construction Companies, June 8-9, pp.50-65, Haifa, Israel.

Martins, E.C. and Terblanche, F. (2000), 'Building organizational culture that stimulates creativity and innovation', European Journal of Innovation Management, vol.6, no.1, pp.64-74.

Nelson, R.R., and Winter, S.G. (1982), An Evolutionary Theory of Economic Change, Cambridge, MA, Harvard University Press.

Nonaka, I. \& Takeuchi, H.T. (1995), The Knowledge Creating Company: How Japanese CompaniesCreate the Dynamic of Innovation, Oxford University Press, New York.

Nwilo, P.C. \& Osanwuta, D.A. (2003), 'Knowledge Sharing as a too for Professional Development in Surveying and Geoinformatics in Nigeria', FIG Working Week, April, Paris, pp.13-17.

Reynolds, L. G. and Shister, J. (1949), Job Horizons, Harper, New York.

Rezgui, Y., Lima, C., Wetherill, L., Zarli, A. (2002), 'Knowledge Management for the Construction Industry: The E-Cognos Project', (http://www.itcon.org/2002/12), [accessed on April 5, 2004].
A.M. (2001), 'Perceptions and barriers in implementing knowledge management strategies in large construction organizations', COBRA 2001, RICS Foundation, UK.

Sako, M (1992), Prices, Quality and Trust: Inter firm Relations in Britain and Japan, Cambridge University Press, Cambridge.

Senge, P.M. (1990), The Fifth Discipline: The Art and Practice of the Learning Organization, Doubleday, New York.

Smack, J.C. and Dawson, L. A. (1993), 'Team partnership: creating an empowerment work place', American Society of Quality Congress Transactions, Boston, USA.

Tushman, M.L. and O'Reilly, C.A. III. (1997), Winning through Innovation: A Practical Guide to Leading Organizational Change and Renewal, Harvard Business School Press, Boston, MA.

Tsui (2002), 'Technologies for personal and peer to peer (P2P) knowledge management', CSC leading edge forum technology grant report, (http://www2.csc.com/lef/programs/grants/finalpapers/ tsui_final_P2PKM.pdf), [accessed on Sep. 02, 2003].

Yahya, S. (2002), 'Managing human resources toward achieving knowledge management', Journal of Knowledge Management, vol.6, no.5, pp.457-468.

Yisa, S.B. (1996). 'A review for changes in the UK construction industry: The implications for the marketing of construction services', European Journal of Marketing, vol.3, no.3, pp.47-65. 